\title{
Prevalence and Risk Factors Associated with the Occurrence of Autoimmune Diseases in Patients with Alopecia Areata
}

\section{Kumutnart Chanprapaph (DD Thipprapai Mahasaksiri (D) Chaninan Kositkuljorn Kanchana Leerunyakul (iD) Poonkiat Suchonwanit (D)}

Division of Dermatology, Department of Medicine, Faculty of Medicine, Ramathibodi Hospital, Mahidol University, Bangkok, Thailand
Correspondence: Poonkiat Suchonwanit Division of Dermatology, Department of Medicine, Faculty of Medicine, Ramathibodi Hospital, Mahidol University, 270 Rama VI Road, Ratchathewi, Bangkok, 10400, Thailand

Tel +66-2-20I I I4I

Fax +66-2-20I-I2II ext 4

Email poonkiat@hotmail.com
Background: Increased rates of autoimmune diseases (ADs) have been reported in association with alopecia areata (AA); however, the risk factors for coexisting ADs in AA patients have been poorly investigated.

Objective: To evaluate the prevalence and factors associated with $\mathrm{AD}$ comorbidities in patients with AA.

Methods: This case-control study included patients diagnosed with AA between January 2000 and March 2020. Individuals with AA, both with and without concomitant ADs, were statistically compared. Variables significantly associated with coexisting ADs were identified using univariate and multivariate logistic regression analyses. Multinomial logistic regression analysis was performed to identify the specific risk factors for each concomitant AD.

Results: Among the 615 patients with AA, comorbid ADs were found in $76(12.4 \%)$. Autoimmune thyroid disease (AITD) exhibited the highest frequency ( $\mathrm{n}=42,6.8 \%$ ), followed by vitiligo $(\mathrm{n}=15,2.4 \%)$, and systemic lupus erythematosus (SLE) $(\mathrm{n}=12$, $2.0 \%$ ). Logistic regression analyses revealed that female sex (odds ratio $[\mathrm{OR}]=2.45,95 \%$ confidence interval $[\mathrm{CI}]=1.24-4.82 ; \mathrm{P}=0.011)$, nail abnormalities $(\mathrm{OR}=2.49,95 \% \mathrm{CI}=$ 1.14-5.46; $\mathrm{P}=0.023)$, and atopic diseases $(\mathrm{OR}=1.98,95 \% \mathrm{CI}=1.09-2.43 ; \mathrm{P}<0.001)$ were significantly associated with coexisting ADs. Regarding each concomitant $\mathrm{AD}$, nail abnormalities were an associated factor for AITD $(\mathrm{OR}=4.65,95 \% \mathrm{CI}=1.96-7.24 ; \mathrm{P}=0.01)$, whereas coexisting atopic diseases were demonstrated as a predictor of vitiligo $(\mathrm{OR}=2.48$, $95 \% \mathrm{CI}=1.43-4.58 ; \mathrm{P}=0.02)$. Female sex $(\mathrm{OR}=1.61,95 \% \mathrm{CI}=1.18-4.27 ; \mathrm{P}=0.04)$ and family history of $\mathrm{AD}(\mathrm{OR}=1.85,95 \% \mathrm{CI}=1.26-4.19 ; \mathrm{P}=0.03)$ were predictors of SLE. Conclusion: This study suggests that female AA patients with nail abnormalities and atopic diseases have increased rates of $\mathrm{AD}$ comorbidities. A thorough review of systems for associated factors can help physicians screen for concomitant ADs.

Keywords: AA, comorbidity, hair loss, non-scarring alopecia, predictor, systemic disorders

\section{Introduction}

Alopecia areata (AA) is an immune-mediated disorder characterized by nonscarring hair loss. It affects individuals of all ages, sexes, and races with an estimated lifetime prevalence of $2 \%$ worldwide. ${ }^{1,2}$ AA manifests as well-defined patches of hair loss with characteristic exclamation mark hairs on the scalp and other hairbearing areas that may progress to total scalp (alopecia totalis [AT]) or complete body (alopecia universalis [AU]) hair loss. ${ }^{3-6}$ Nail abnormalities have occasionally been observed, ${ }^{7}$ with nail pitting being the most common symptom. ${ }^{8}$ The disease is 
considered globally significant, with major psychological impacts due to the variability of treatment responses and chronic, relapsing, and unpredictable clinical course. ${ }^{9}$

The pathogenesis of AA is unclear; however, an autoimmune etiology with genetic predisposition has been hypothesized. ${ }^{10-12}$ The presence of various circulating autoantibodies and autoantigens at the affected scalp of AA patients underlines its autoimmune process. ${ }^{13}$ Additionally, genome-wide association studies have reported several genomic regions related to AA. ${ }^{14}$ Epigenetics, including environment and stress, may also be associated with disease occurrence. ${ }^{15}$ Associations between AA and several autoimmune diseases (ADs) have been previously reported. ${ }^{16,17} \mathrm{AA}$ was found to coexist with other ADs, including autoimmune thyroid diseases (AITD), vitiligo, systemic lupus erythematosus (SLE), rheumatoid arthritis, type 1 diabetes mellitus, ulcerative colitis, coeliac disease, and scleroderma. ${ }^{7,18-21}$ However, the frequency of these comorbid ADs was reported differently among geographical populations. ${ }^{18}$

Awareness of potential comorbid ADs, in-depth investigations, and prompt management are crucial for improving the treatment outcomes of AA. Although AA patients are predisposed to comorbid ADs, factors influencing the development of coexisting ADs remain poorly investigated. We aimed to determine the spectrum of $\mathrm{AD}$ and factors associated with comorbid ADs in a cohort of Thai AA patients; additionally, specific factors were evaluated for each AD.

\section{Materials and Methods Study Design}

This single-center case-control study was conducted in accordance with the principles of the Declaration of Helsinki. The protocol was approved by the Mahidol University Institutional Review Board for Ethics in Human Research (MURA2019/250). All subjects included were classified based on the presence (cases) or absence (controls) of AD. Informed consent was waived for this study, and data anonymization was performed before analysis.

\section{Study Participants and Data Collection}

Subjects included patients clinically and/or histologically diagnosed with AA between January 2000 and March 2019 from the outpatient dermatology clinic at Ramathibodi Hospital, Bangkok, Thailand; a minimum follow-up period of one year was required. Data regarding sex, age at AA onset, duration of AA, family history of
AA, family history of $\mathrm{AD}$, AA subtypes (ie, patch-type, multiple patches, AT/AU, and ophiasis), severity of AA according to the Severity of Alopecia Tool Score (SALT), nail abnormalities, comorbidities, and laboratory results were obtained from electronic medical records from January 2000 to March 2020. Patients with incomplete personal or clinical records, serological or histological data for the diagnosis of AA and comorbidities, or other hair and scalp disorders were excluded.

Comorbid ADs in this study were defined according to the modified version of Witebsky's postulates. ${ }^{22}$ Atopic diseases comprised allergic rhinitis, asthma, and atopic dermatitis. AITDs included Graves' disease and Hashimoto's thyroiditis. AD and other comorbidities were diagnosed based on medical records from previous specialist examinations. To ensure diagnostic validity, we limited subjects to those with a written report from a specialist confirming their diagnosis and at least two visits to our clinic under this diagnosis. Patient demographics and clinical characteristics were compared between groups, and further subgroup analysis was performed to identify specific risk factors for each AD.

\section{Statistical Analysis}

Analyses were performed using SPSS Statistics version 18.0 (SPSS Inc., Chicago, IL, USA). To detect a modestly sized odds ratio (OR), the sample size was estimated based on data from a previous study regarding the prevalence of $\mathrm{AD}$ in patients with $\mathrm{AA} .{ }^{18}$ At least 375 patients were required to yield a statistical power of $95 \%$ and a twosided significance level of 5\%. Categorical variables were reported as proportions, and continuous variables were expressed as means \pm standard deviations (SDs) or medians (interquartile ranges, IQR). Differences between AA patients with and without AD were determined using the Chi-square, Fisher's exact, Mann-Whitney U, or independent samples t-tests, as appropriate.

ORs and 95\% confidence intervals (CIs) were calculated for the entire cohort as an estimate of the relative risk and were used to describe the associations. To initially assess associations between factors of interest and comorbid ADs, univariate analysis was performed, comparing demographics and clinical characteristics. Multivariable logistic regression analysis was performed to adjust for potential confounding where appropriate and identify factors associated with concurrent AD. Multinomial logistic regression was used to evaluate the relationships between potential risk factors and each of the reported ADs. Two- 
tailed P-values $<0.05$ were considered statistically significant and analyzed without any formal adjustment for multiple comparisons.

\section{Results}

\section{Demographics and Clinical Characteristics}

Six hundred fifteen patients with AA met the inclusion criteria; $76(12.4 \%)$ were assigned to the AA with $\mathrm{AD}$ group and 539 $(87.6 \%)$ were in the AA without AD group. Table 1 presents the demographics and clinical characteristics of patients with and without AD. Most patients were females (61 [80.2\%] in the $\mathrm{AD}$ group and 351 [65\%] in the non-AD group), with a significantly higher proportion in the $\mathrm{AD}$ group $(\mathrm{P}=0.008)$. The mean age at AA onset was $37.9 \pm 11.1$ years in patients with AD compared to those without AD (36.8 \pm 10.7 years; $\mathrm{P}=0.618$ ). Although age at onset was stratified into five subgroups, comparison between the two groups remained compatible $(\mathrm{P}=0.737)$. There were also no statistically significant differences between groups for the median duration of AA

Table I Demographic and Clinical Characteristics of 615 Included Patients with Alopecia Areata

\begin{tabular}{|c|c|c|c|}
\hline Variables & $\begin{array}{c}\text { AA with AD } \\
(n=76)\end{array}$ & $\begin{array}{c}\text { AA without AD } \\
(n=539)\end{array}$ & P-value \\
\hline $\begin{array}{l}\text { Sex, n (\%) } \\
\text { - Male } \\
\text { - Female }\end{array}$ & $\begin{array}{l}15(19.8) \\
61(80.2)\end{array}$ & $\begin{array}{l}188(35) \\
35 \mid(65)\end{array}$ & $0.008 *$ \\
\hline Age at AA onset, year, mean (SD) & $37.9(11.1)$ & $36.8(10.7)$ & 0.618 \\
\hline $\begin{aligned} \text { Age at AA onset, year, n (\%) } \\
\text { - }<18 \\
\text { - } 18-30 \\
\text { - } 31-45 \\
\text { - } 46-60 \\
\text { - }>60\end{aligned}$ & $\begin{array}{l}5(6.6) \\
21(27.6) \\
18(23.7) \\
19(25.0) \\
13(17.1)\end{array}$ & $\begin{array}{l}43(8.0) \\
173(32.1) \\
140(26.0) \\
108(20.0) \\
75(13.9)\end{array}$ & 0.737 \\
\hline Duration of disease, month, median (IQR) & $8(4.5-23.5)$ & $5(3-11)$ & 0.09 \\
\hline $\begin{array}{l}\text { Duration of disease, } \mathrm{n}(\%) \\
\bullet<\text { I year } \\
\bullet>\text { I year }\end{array}$ & $\begin{array}{l}43(56.6) \\
33(43.4)\end{array}$ & $\begin{array}{l}419(77.8) \\
120(22.2)\end{array}$ & $<0.001 *$ \\
\hline $\begin{array}{l}\text { AA subtype, n (\%) } \\
\text { - Patch-type AA } \\
\text { - Multiple AA } \\
\text { - AT/AU } \\
\text { - Ophiasis }\end{array}$ & $\begin{array}{c}45(59.2) \\
22(28.9) \\
8(10.5) \\
1(1.4)\end{array}$ & $\begin{array}{l}380(70.5) \\
109(20.3) \\
39(7.2) \\
11(2.0)\end{array}$ & 0.192 \\
\hline $\begin{array}{l}\text { Severity of AA (SALT score), } \mathrm{n}(\%) \\
\text { - } 0-25 \% \\
\text { - } 26-50 \% \\
\text { - } 51-75 \% \\
\text { - } 76-100 \%\end{array}$ & $\begin{array}{l}51(67.1) \\
12(15.8) \\
5(6.6) \\
8(10.5)\end{array}$ & $\begin{array}{l}409(75.9) \\
48(8.9) \\
42(7.8) \\
40(7.4)\end{array}$ & 0.181 \\
\hline Body hair involvement, n (\%) & $6(8.2)$ & $16(3.0)$ & $0.031 *$ \\
\hline Nail abnormalities, n (\%) & $13(17.1)$ & $41(7.6)$ & $0.006 *$ \\
\hline Atopic diseases, n (\%) & $30(39.4)$ & $112(20.7)$ & $<0.00 I^{*}$ \\
\hline Family history of AA, n (\%) & $2(2.6)$ & $22(4.1)$ & 0.541 \\
\hline Family history of AD, n (\%) & $6(7.9)$ & $19(3.5)$ & 0.071 \\
\hline
\end{tabular}

Note: *Statistically significant.

Abbreviations: AA, alopecia areata; AD, autoimmune disease; AT/AU, alopecia totalis/alopecia universalis; IQR, interquartile range; SALT, Severity of Alopecia Tool; SD, standard deviation. 
$(\mathrm{P}=0.09)$; however, when disease duration was stratified per year, more patients with $\mathrm{AD}$ had a duration $>1$ year $(\mathrm{P}<0.001)$. Fifty-four AA patients presented with nail abnormalities, including nail pitting $(n=50,7.1 \%)$, trachyonychia $(n=5$, $0.8 \%)$, and onychorrhexis $(n=5,0.8 \%)$. Patients with AD had a higher proportion of body hair involvement $(8.2 \%$ vs $3.0 \%$; $\mathrm{P}=0.031$ ), nail involvement (17.1\% vs $7.6 \% ; \mathrm{P}=0.006)$, and atopic diseases $(39.4 \%$ vs $20.7 \%$; $<<0.001)$. No statistically significant differences were observed between patients with and without $\mathrm{AD}$ regarding $\mathrm{AA}$ clinical subtypes $(\mathrm{P}=0.192)$, severity of $\mathrm{AA}(\mathrm{P}=0.181)$, family history of $\mathrm{AA}(\mathrm{P}=0.541)$, or family history of $\mathrm{AD}(\mathrm{P}=0.071)$.

\section{Autoimmune Diseases and Other Comorbidities}

Seven ADs were reported in our cohort, and none of the patients exhibited more than one type. The most prevalent
AD was AITD $(n=42,6.8 \%)$, followed by vitiligo $(n=15$, $2.4 \%)$, SLE $(n=12,2.0 \%)$, psoriasis $(n=3,0.5 \%)$, rheumatoid arthritis $(n=2,0.3 \%)$, myasthenia gravis $(n=1,0.2 \%)$, and systemic sclerosis $(n=1,0.2 \%)$. Hashimoto thyroiditis and Graves' disease were found in 23 (4\%) and $19(3 \%)$ patients with AITD, respectively. A comparison of the prevalence of non-AD comorbidities revealed that atopic diseases were predominantly found in patients with ADs $(39.4 \%$ vs $20.7 \%)$, while the rest were comparable between groups (Table 2). The most common atopic condition was atopic dermatitis $(n=69,11.2 \%)$, followed by allergic rhinitis $(\mathrm{n}=54,8.8 \%)$, and asthma $(\mathrm{n}=19,3.1 \%)$.

\section{Factors Associated with Autoimmune Disease Comorbidity in Alopecia Areata}

In the logistic regression model, factors linked to $\mathrm{AD}$ and AA via univariate analysis were female sex $(\mathrm{OR}=2.20$,

Table 2 Spectrum and Prevalence of Comorbidities Observed in 615 Patients with Alopecia Areata

\begin{tabular}{|c|c|c|c|}
\hline Variables & $\begin{array}{c}\text { AA with AD } \\
(n=76)\end{array}$ & $\begin{array}{c}\text { AA without AD } \\
(n=539)\end{array}$ & P-value \\
\hline \multicolumn{4}{|l|}{ Autoimmune conditions, $\mathrm{n}(\%)$} \\
\hline - AITD & $42(6.8)$ & - & - \\
\hline - Vitiligo & $15(2.4)$ & - & - \\
\hline - SLE & $12(2.0)$ & - & - \\
\hline - Psoriasis & $3(0.5)$ & - & - \\
\hline - Rheumatoid arthritis & $2(0.3)$ & - & - \\
\hline - Myasthenia gravis & $\mathrm{I}(0.2)$ & - & - \\
\hline - Systemic sclerosis & $\mathrm{I}(0.2)$ & - & - \\
\hline \multicolumn{4}{|l|}{ Other comorbidities, n (\%) } \\
\hline - Atopic diseases & $30(39.4)$ & $112(20.7)$ & $<0.001 *$ \\
\hline - Iron deficiency anemia & I (I.3) & $6(1.1)$ & 0.876 \\
\hline - Viral hepatitis B & $\mathrm{I}(\mathrm{I} .3)$ & $5(0.9)$ & 0.747 \\
\hline - HIV infection & $\mathrm{I}(\mathrm{I} .3)$ & $6(1.1)$ & 0.876 \\
\hline - Hypertension & $2(1.5)$ & $10(1.8)$ & 0.646 \\
\hline - Dyslipidemia & I (I.3) & $9(1.6)$ & 0.309 \\
\hline - Type 2 diabetes mellitus & $3(3.9)$ & $24(4.4)$ & 0.841 \\
\hline - Malignancy & $2(2.6)$ & $18(3.3)$ & 0.744 \\
\hline - Psychiatric disorders & 0 & $4(0.7)$ & 0.611 \\
\hline
\end{tabular}

Note: *Statistically significant.

Abbreviations: AA, alopecia areata; AD, autoimmune disease; AITD, autoimmune thyroid disease; HIV, human immunodeficiency virus; SLE, systemic lupus erythematosus. 
95\% $\mathrm{CI}=1.14-4.23 ; \mathrm{P}=0.018), \quad \mathrm{AA}$ duration $>1$ year $(\mathrm{OR}=1.60,95 \% \mathrm{CI}=1.20-4.49 ; \mathrm{P}=0.041)$, body hair involvement $(\mathrm{OR}=2.91,95 \% \mathrm{CI}=1.03-8.28 ; \mathrm{P}=0.043)$, nail abnormalities $(\mathrm{OR}=2.83,95 \% \mathrm{CI}=1.13-5.05: \mathrm{P}=0.021)$, and atopic diseases $(\mathrm{OR}=1.84, \quad 95 \% \quad \mathrm{CI}=1.12-2.51$; $\mathrm{P}<0.001)$. Multivariable logistic regression analysis, adjusted for potential confounders in the univariate model, revealed that female sex $(\mathrm{OR}=2.45,95 \%$ $\mathrm{CI}=1.24-4.82 ; \mathrm{P}=0.011)$, nail abnormalities $(\mathrm{OR}=2.49$, 95\% $\mathrm{CI}=1.14-5.46: \quad \mathrm{P}=0.023)$, and atopic diseases $(\mathrm{OR}=1.98,95 \% \mathrm{CI}=1.09-2.43 ; \mathrm{P}<0.001)$ were factors associated with the occurrence of $\mathrm{AD}$ in patients with AA, while other features, including an AA duration $>1$ year and body hair involvement, were not (Table 3 ).

\section{Factors Associated with Each} Autoimmune Disease in Alopecia Areata Unadjusted and adjusted multinomial logistic regression analyses were performed to assess whether AD was associated with the variables examined and obtain the odds of pairwise comparisons between patients without $\mathrm{AD}$ and each AD subgroup. Patients without AD represented the reference category. Patients with psoriasis, rheumatoid arthritis, myasthenia gravis, and systemic sclerosis were excluded as the risk could not be analyzed due to the small number of cases. Table 4 presents details regarding significant variables in the adjusted multinomial logistic regression analysis. Compared to AA individuals without AD, nail abnormalities were an associated factor for AITD

Table 3 Univariate and Multivariable Logistic Regression Analyses for the Risk of Coexisting Autoimmune Diseases in Patients with Alopecia Areata

\begin{tabular}{|c|c|c|c|c|}
\hline Variables & OR $(95 \% \mathrm{Cl})$ & P-value & $\begin{array}{c}\text { Adjusted } \\
\text { OR }(95 \% \mathrm{Cl})\end{array}$ & P-value \\
\hline Female & $2.20(1.14-4.23)$ & $0.018^{*}$ & $2.45(1.24-4.82)$ & $0.011 *$ \\
\hline $\begin{aligned} \text { Age at AA onset } \\
-<18 \\
\text { - } 18-30 \\
\text { - } 31-45 \\
-46-60 \\
->60\end{aligned}$ & $\begin{array}{l}\text { Reference } \\
1.22(0.28-1.86) \\
1.45(0.22-1.91) \\
1.64(0.23-2.62) \\
1.72(0.21-3.45)\end{array}$ & $\begin{array}{l}0.497 \\
0.199 \\
0.514 \\
0.603\end{array}$ & & \\
\hline Duration of disease $>$ I year & $1.60(1.20-4.49)$ & $0.04 I^{*}$ & $1.13(0.69-2.01)$ & 0.072 \\
\hline $\begin{array}{l}\text { AA subtype } \\
\text { - Patch-type AA } \\
\text { - Multiple AA } \\
\text { - AT/AU } \\
\text { - Ophiasis }\end{array}$ & $\begin{array}{l}\text { Reference } \\
1.24(0.29-2.52) \\
0.62(0.39-2.15) \\
0.89(0.06-1.42)\end{array}$ & $\begin{array}{l}0.072 \\
0.845 \\
0.999\end{array}$ & & \\
\hline $\begin{array}{l}\text { Severity of AA (SALT score) } \\
\text { - } 0-25 \% \\
\text { - } 26-50 \% \\
\text { - } 51-75 \% \\
\text { - } 76-100 \%\end{array}$ & $\begin{array}{l}\text { Reference } \\
\text { I.4I (0.82-3.59) } \\
0.94(0.11-6.67) \\
1.69(0.21-2.33)\end{array}$ & $\begin{array}{l}0.153 \\
0.870 \\
0.555\end{array}$ & & \\
\hline Body hair involvement & $2.91(1.03-8.28)$ & $0.043^{*}$ & $2.71(0.90-8.16)$ & 0.076 \\
\hline Nail abnormalities & $2.38(1.13-5.05)$ & $0.021^{*}$ & $2.49(1.14-5.46)$ & $0.023^{*}$ \\
\hline Atopic diseases & $\mathrm{I} .84(\mathrm{I} .12-2.5 \mathrm{I})$ & $<0.001 *$ & $1.98(1.09-2.43)$ & $<0.001 *$ \\
\hline Family history of AA & $0.76(0.07-5.06)$ & 0.633 & & \\
\hline Family history of $A D$ & $1.15(0.21-2.68)$ & 0.468 & & \\
\hline
\end{tabular}

Note: *Statistically significant.

Abbreviations: AA, alopecia areata; AD, autoimmune disease; AT/AU, alopecia totalis/alopecia universalis; Cl, confidence interval; OR, odds ratio; SALT, Severity of Alopecia Tool. 


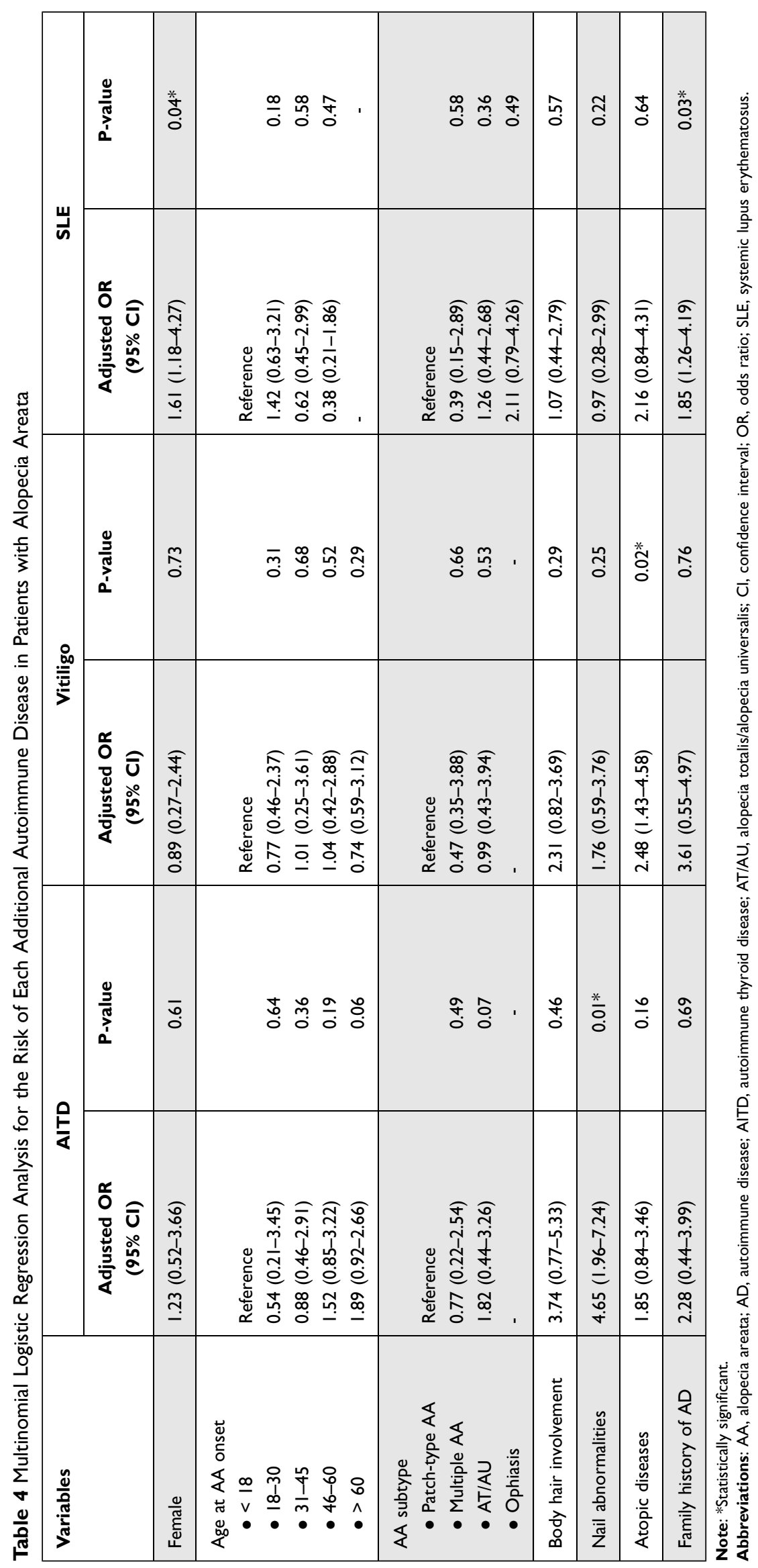


$(\mathrm{OR}=4.65,95 \% \mathrm{CI}=1.96-7.24 ; \mathrm{P}=0.01)$, whereas an age at onset $>60$ years and AT/AU subtype revealed borderline significance $\quad(\mathrm{OR}=1.89, \quad 95 \% \quad \mathrm{CI}=0.92-2.66 ; \quad \mathrm{P}=0.06$; $\mathrm{OR}=1.82, \quad 95 \% \quad \mathrm{CI}=0.44-3.26 ; \quad \mathrm{P}=0.07$, respectively). Concomitant atopic diseases were a specific predictor for vitiligo $(\mathrm{OR}=2.48,95 \% \mathrm{CI}=1.43-4.58 ; \mathrm{P}=0.02)$, while female sex and family history of $\mathrm{AD}$ were significant factors correlated with SLE $(\mathrm{OR}=1.61,95 \% \mathrm{CI}=1.18$ 4.27; $\mathrm{P}=0.04$ and $\mathrm{OR}=1.85,95 \% \mathrm{CI}=1.26-4.19 ; \mathrm{P}=0.03$, respectively).

\section{Discussion}

Several studies suggest a strong association between AA and $\mathrm{AD}$; however, little is known regarding the risk factors for $\mathrm{AD}$. In our study, a relatively large number of subjects demonstrated that the most prevalent $\mathrm{AD}$ in Thais was AITDs; among individuals with AA, female patients with nail abnormalities and atopic diseases were more likely to have additional ADs. Moreover, nail involvement in AA patients with $\mathrm{AD}$ was associated with an increased risk of coexisting AITD, while atopic diseases were associated with vitiligo. Female AA patients with a family history of $\mathrm{AD}$ were more likely to develop SLE.

In this study, approximately $12.4 \%$ of AA patients had an $\mathrm{AD}$, a rate 2.7 -fold higher than that in the general population $(4.5 \%)^{22}$ and comparable to previous reports (12-16\%). ${ }^{19,23}$ The association between AA and other ADs has been previously documented, ${ }^{19,24-28}$ and seven ADs were reported in our study. Compared to previous reports in patients with AA, AITD was the most common AD with prevalence within the expected range (6.8\% vs 7.2-7.4\%); vitiligo and SLE were prevalent higher $(2.4 \%$ vs $0.3-0.9 \%$, and $2 \%$ vs $1.3-1.5 \%$, respectively). ${ }^{16,29}$ In contrast, psoriasis and rheumatoid arthritis were underrepresented $(0.5 \%$ vs $1.9 \%$ and $0.3 \%$ vs $1 \%$, respectively). ${ }^{16}$ The differences in prevalence among different $\mathrm{AD}$ types may be explained by genetic variation and different definitions in previous studies. Patients with $\mathrm{AD}$ are susceptible to other autoimmune conditions, possibly due to commonly shared abnormal gene expression. Several shared genetic polymorphisms have been demonstrated in multiple ADs, including cytotoxic T-lymphocyte-associated protein 4 , protein tyrosine phosphatase nonreceptor type 22 , signal transducer and activator of transcription 4 , and tumor necrosis factor-induced protein $3 .{ }^{30}$ Moreover, evidence suggests that both T helper 1 (Th1) and 2 (Th2) inflammatory cytokines participate in the pathogenesis of AA, providing an association between AA and both $\mathrm{T}$ cell-mediated (eg,
Hashimoto thyroiditis and vitiligo) and antibody-mediated ADs (eg, Graves' disease and SLE). ${ }^{27,31}$

Our study demonstrates the risk factors linked to ADs in AA, including female sex, nail abnormalities, and atopic diseases. ADs have been demonstrated to be more prevalent in women, with approximately $80 \%$ of $\mathrm{AD}$ patients being females. ${ }^{32}$ In our study, female sex was also associated with a 2.4-fold increase in the risk of developing additional ADs, consistent with a previous study comparing characteristics between male and female AA patients.${ }^{33}$ Hormonal changes in females during puberty may play an important role in AD-associated gender disparity. After the onset of puberty, there is an increase in the incidence of ADs. ${ }^{34}$ Elevated estrogen levels were postulated to enhance the humoral immune system, leading to an increased possibility of $\mathrm{AD}$ occurrence in female $\mathrm{AA}$ patients compared to males. ${ }^{35-37}$

Nail changes, often associated with AA, were reported in $10-66 \%$ of patients. ${ }^{38}$ Nail pitting was the most common, followed by trachyonychia. ${ }^{8}$ These were also observed in patients with other ADs, including AITD, psoriasis, and vitiligo. ${ }^{39}$ While the pathophysiology of these changes is not clearly understood, inflammatory cells targeting the nail may cause abnormal keratinization of the matrix, leading to nail plate changes. Abnormal nail findings in AA correlate with disease severity and poor prognosis. ${ }^{40-43}$ Our further exploration revealed that AA patients with nail changes were at increased risks of other ADs. We hypothesize that nail abnormalities indicate increased immunogenicity in areas other than hair follicles and may help determine individuals with increased susceptibility for developing multiple ADs.

Several studies have reported an association between AA and atopic diseases, with variable prevalence rates (10$60 \%)^{9,19,27,44-47}$ AA responds poorly to treatment in the presence of atopy. ${ }^{40}$ The prevalence of atopic diseases in our study was $23.1 \%$, comparable with the result of a previous report (24.9\%). ${ }^{16}$ Furthermore, atopic diseases were identified as a significant predictor of comorbid ADs, corresponding with a previous large-scale case-control study demonstrating the relationship between AA, ADs, and atopic diseases. ${ }^{19}$ Mechanisms underlying this association remain inconclusive. Shared genetics are theorized to play a role in their association since filaggrin gene mutations were found to be predictors of more severe AA in patients with comorbid atopic diseases. ${ }^{48,49}$ However, AA is considered a predominantly Th1-mediated AD, caused by CD4+ and CD8+ T cells involving anagen hair follicles. ${ }^{10,50,51}$ The significance of both Th1 and Th2 cytokine pathways in AA has been 
demonstrated in animal models. ${ }^{52}$ Since atopic diseases provide predominant Th2-type inflammation, ${ }^{53,54}$ similar Th2 response patterns in AA and atopic diseases may account for their association. ${ }^{46}$ The complex interplay among cytokines and immune cells in AA individuals with atopic diseases may cause aberrant interactions between patients' immune and organ systems, resulting in an increased risk of additional ADs.

Our study further explored specific risk factors for each coexisting $\mathrm{AD}$ in AA patients using a multinomial logistic regression model; only AITD, vitiligo, and SLE were eligible for analysis due to the sufficient sample size. Several studies have documented the association between AITD and severe forms of $\mathrm{AA},{ }^{27,29,55-58}$ and a large cross-sectional study has reported an age at AA onset of $>60$ years to be a predictor for AITD. ${ }^{16}$ Our study suggests otherwise; nail changes were a risk factor for comorbid AITD in our cohort. However, AT/ AU subtype and age at onset $>60$ years showed a borderline association, supporting previous findings. Currently, there is no emerging evidence regarding the causal relationship or interaction between AA and AITD.

Atopic diseases were found to be a specific risk factor for concurrent vitiligo in our AA patients. This result is supported by a meta-analysis and two large-scale studies that identified the link between atopic diseases and vitiligo. ${ }^{48,59,60}$ While an age at AA onset of $>20$ years revealed a marked elevation in the risk of vitiligo in a previous study, our data failed to demonstrate this association. ${ }^{16}$ The mechanisms of the co-occurrence of atopic diseases, vitiligo, and AA remain unknown. The autoimmune etiology of vitiligo and its association with AA support the possibility that atopic diseases may be apparent in AA patients with vitiligo, while the underlying mechanisms of their association may be explained by the activation of thymic stromal lymphopoietin and Th17. ${ }^{48,61-65}$ Their association may also have therapeutic implications, as the conditions have demonstrated therapeutic responses to Janus kinase inhibitors. ${ }^{66}$

Several observational studies have described the coexistence of AA and SLE; however, information on predictors of their association remains scarce and inconclusive. ${ }^{16,56,67} \mathrm{~A}$ population-based study identified female sex, age at onset $>40$ years, and Jewish ancestry as risk factors for concurrent SLE and $\mathrm{AA} ;{ }^{68}$ on the contrary, another large-scale study indicated younger age at onset to be a predictor. ${ }^{16}$ Our study found female sex and a positive family history of $\mathrm{AD}$ to be predictors for SLE comorbidity in AA patients, consistent with female predominance, which exhibits clustering within families for a wide range of reported ADs. ${ }^{69-71}$ AA's clinical presentation may mimic patchy, lupus-specific, nonscarring alopecia in SLE, leading to misdiagnoses. Trichoscopic findings of hair shaft hypopigmentation and prominent and thick arborizing blood vessels could provide a diagnostic distinction of nonscarring alopecia in SLE and AA; $;^{72}$ however, histopathological and immunohistochemical studies should be performed in uncertain cases. ${ }^{73-75}$ The mechanism underlying the association between AA and SLE has not been fully elucidated. Both diseases may share a pathogenic role for CD4+ T cells (both Th1 and Th2), producing autoantibodies for several antigens, thus resulting in the subsequent induction of autoimmunity. ${ }^{16,19,50,76-81}$

Our study had several limitations. First, owing to its retrospective design, some data were unavailable. Second, it was performed at a single tertiary referral center, which may have attracted more complex patients and, thus, higher AD cases. Third, the population included in this study was homogeneous, which may limit the generalizability of the results. Fourth, all family history data were obtained from patients' statements; thus, the prevalence of family history may have been underestimated. Fifth, detection bias may have occurred due to the different follow-up durations among AA participants, contributing to the underestimation of AD prevalence. Finally, the study methods precluded analysis of the temporal relationship between AA and ADs and had limited power due to multiple comparisons. To confirm our results and better identify associations between $\mathrm{AA}$ and $\mathrm{AD}$ comorbidities, further prospective, longitudinal, multicenter studies with a larger sample size are required.

\section{Conclusion}

Our study revealed that female AA patients with nail abnormalities and atopic diseases were more likely to have additional ADs. Although it is unclear whether ADs in AA patients could be comorbidities with their own specific dysreactivity of the immune system or AA-dependent diseases, physicians should perform a thorough review of medical history, organ system symptoms, physical examination, and appropriate screenings for ADs in patients with AA. Despite the lack of study power due to the small number of subjects in each $\mathrm{AD}$ subgroup, targeted reviews of specific risks for comorbid AITD (ie, nail abnormalities, age at AA onset $>60$ years, and AT/AU subtype), vitiligo (ie, atopic diseases), and SLE (ie, female and family history of AD) in AA patients may be important to assess the risk of developing additional ADs. 


\section{Data Sharing Statement}

All datasets are available from the corresponding author on reasonable request.

\section{Ethics Approval and Consent to Participate}

This single-center case-control study was conducted in accordance with the principles of the Declaration of Helsinki. The protocol was approved by the Mahidol University Institutional Review Board for Ethics in Human Research (MURA2019/250). Informed consent was waived, and data anonymization was performed before analysis.

\section{Funding}

The authors received no financial support for this research.

\section{Disclosure}

The authors have no conflicts of interest to declare.

\section{References}

1. Safavi K. Prevalence of alopecia areata in the first national health and nutrition examination survey. Arch Dermatol. 1992;128(5):702. doi:10.1001/archderm.1992.01680150136027

2. Mirzoyev SA, Schrum AG, Davis MDP, Torgerson RR. Lifetime incidence risk of alopecia areata estimated at $2.1 \%$ by Rochester epidemiology project, 1990-2009. J Invest Dermatol. 2014;134 (4):1141-1142. doi:10.1038/jid.2013.464

3. Strazzulla LC, Wang EHC, Avila L, et al. Alopecia areata: disease characteristics, clinical evaluation, and new perspectives on pathogenesis. J Am Acad Dermatol. 2018;78(1):1-12. doi:10.1016/j. jaad.2017.04.1141

4. Rattananukrom T, Suchonwanit P. Are drug treatment strategies really effective against alopecia areata? Expert Opin Pharmacother 2021;22(3):257-260. doi:10.1080/14656566.2020.1854728

5. Khunkhet S, Vachiramon V, Suchonwanit P. Trichoscopic clues for diagnosis of alopecia areata and trichotillomania in Asians. Int $J$ Dermatol. 2017;56(2):161-165. doi:10.1111/ijd.13453

6. Meephansan J, Thummakriengkrai J, Ponnikorn S, Yingmema W, Deenonpoe R, Suchonwanit P. Efficacy of topical tofacitinib in promoting hair growth in non-scarring alopecia: possible mechanism via VEGF induction. Arch Dermatol Res. 2017;309(9):729-738. doi:10.1007/s00403-017-1777-5

7. Islam N, Leung PS, Huntley AC, Gershwin ME. The autoimmune basis of alopecia areata: a comprehensive review. Autoimmun Rev. 2015;14(2):81-89. doi:10.1016/j.autrev.2014.10.014

8. Tosti A, Morelli R, Bardazzi F, Peluso AM. Prevalence of nail abnormalities in children with alopecia areata. Pediatr Dermatol. 1994;11(2):112-115. doi:10.1111/j.1525-1470.1994.tb00562.x

9. Alkhalifah A, Alsantali A, Wang E, McElwee KJ, Shapiro J. Alopecia areata update: part I. Clinical picture, histopathology, and pathogenesis. J Am Acad Dermatol. 2010;62(2):177-188, quiz 189-190. doi:10.1016/j.jaad.2009.10.032

10. Gilhar A, Ullmann Y, Berkutzki T, Assy B, Kalish RS. Autoimmune hair loss (alopecia areata) transferred by $\mathrm{T}$ lymphocytes to human scalp explants on SCID mice. J Clin Invest. 1998;101(1):62-67. doi:10.1172/JCI551
11. Suchonwanit P, Hector CE, Bin Saif GA, McMichael AJ. Factors affecting the severity of central centrifugal cicatricial alopecia. Int $J$ Dermatol. 2016;55(6):e338-343. doi:10.1111/ijd.13061

12. Suchonwanit P, McMichael AJ. Alopecia in association with malignancy: a review. Am $J$ Clin Dermatol. 2018;19(6):853-865. doi:10.1007/s40257-018-0378-1

13. Rajabi F, Drake LA, Senna MM, Rezaei N. Alopecia areata: a review of disease pathogenesis. Br J Dermatol. 2018;179(5):1033-1048. doi:10.1111/bjd.16808

14. Petukhova L, Duvic M, Hordinsky M, et al. Genome-wide association study in alopecia areata implicates both innate and adaptive immunity. Nature. 2010;466(7302):113-117. doi:10.1038/ nature 09114

15. Ikeda T. Produced alopecia areata based on the focal infection theory and mental motive theory. Dermatologica. 1967;134(1):1-11. doi: $10.1159 / 000254233$

16. Chu SY, Chen YJ, Tseng WC, et al. Comorbidity profiles among patients with alopecia areata: the importance of onset age, a nationwide population-based study. J Am Acad Dermatol. 2011;65(5):949956. doi:10.1016/j.jaad.2010.08.032

17. Leerunyakul K, Suchonwanit P. Asian Hair: a Review of Structures, Properties, and Distinctive Disorders. Clin Cosmet Investig Dermatol. 2020;13:309-318. doi:10.2147/ccid.S247390

18. Lee $\mathrm{S}$, Lee $\mathrm{H}$, Lee $\mathrm{CH}$, Lee WS. Comorbidities in alopecia areata: a systematic review and meta-analysis. $J$ Am Acad Dermatol. 2019;80 (2):466-477 e416. doi:10.1016/j.jaad.2018.07.013

19. Barahmani N, Schabath MB, Duvic M. National Alopecia Areata R. History of atopy or autoimmunity increases risk of alopecia areata. $J$ Am Acad Dermatol. 2009;61(4):581-591. doi:10.1016/j. jaad.2009.04.031

20. Leerunyakul K, Suchonwanit P. Evaluation of hair density and hair diameter in the adult Thai population using quantitative trichoscopic analysis. Biomed Res Int. 2020;2020:2476890. doi:10.1155/2020/ 2476890

21. Suchonwanit P, Triamchaisri S, Wittayakornrerk S, Rattanakaemakorn P. Leprosy Reaction in Thai Population: a 20year retrospective study. Dermatol Res Pract. 2015;2015:253154. doi: $10.1155 / 2015 / 253154$

22. Hayter SM, Cook MC. Updated assessment of the prevalence, spectrum and case definition of autoimmune disease. Autoimmun Rev. 2012;11(10):754-765. doi:10.1016/j.autrev.2012.02.001

23. Safavi KH, Muller SA, Suman VJ, Moshell AN, Melton LJ. Incidence of alopecia areata in Olmsted County, Minnesota, 1975 through 1989. Mayo Clin Proc. 1995;70(7):628-633. doi:10.4065/ 70.7.628

24. Ahmed I, Nasreen S, Bhatti R. Alopecia areata in children. $J$ Coll Physicians Surg Pak. 2007;17(10):587-590. doi:10.2007/ JCPSP. 587590

25. Sharma VK, Kumar B, Dawn G. A clinical study of childhood alopecia areata in Chandigarh, India. Pediatr Dermatol. 1996;13 (5):372-377. doi:10.1111/j.1525-1470.1996.tb00703.x

26. Huang KP, Mullangi S, Guo Y, Qureshi AA. Autoimmune, atopic, and mental health comorbid conditions associated with alopecia areata in the United States. JAMA Dermatol. 2013;149(7):789-794. doi:10.1001/jamadermatol.2013.3049

27. Goh C, Finkel M, Christos PJ, Sinha AA. Profile of 513 patients with alopecia areata: associations of disease subtypes with atopy, autoimmune disease and positive family history. $J$ Eur Acad Dermatol Venereol. 2006;20(9):1055-1060. doi:10.1111/j.14683083.2006.01676.x

28. Cunliffe WJ, Hall R, Stevenson CJ, Weightman D. Alopecia areata, thyroid disease and autoimmunity. Br J Dermatol. 1969;81(12):877881. doi:10.1111/j.1365-2133.1969.tb15967.x

29. You HR, Kim SJ. Factors associated with severity of alopecia areata. Ann Dermatol. 2017;29(5):565-570. doi:10.5021/ad.2017.29.5.565 
30. Gregersen PK, Olsson LM. Recent advances in the genetics of autoimmune disease. Annu Rev Immunol. 2009;27:363-391. doi:10.1146/ annurev.immunol.021908.132653

31. Ahmed AM, Barahmani N, Duvic M. National Alopecia Areata R. Familial alopecia areata and chronic thrombocytopenia. J Am Acad Dermatol. 2008;58(5 Suppl 1):S75-77. doi:10.1016/j. jaad.2007.05.017

32. Invernizzi P, Pasini S, Selmi C, Gershwin ME, Podda M. Female predominance and $\mathrm{X}$ chromosome defects in autoimmune diseases. $J$ Autoimmun. 2009;33(1):12-16. doi:10.1016/j.jaut.2009.03.005

33. Lundin M, Chawa S, Sachdev A, Bhanusali D, Seiffert-Sinha K, Sinha AA. Gender differences in alopecia areata. $J$ Drugs Dermatol. 2014;13(4):409-413.

34. Chitnis T. Role of puberty in multiple sclerosis risk and course. Clin Immunol. 2013;149(2):192-200. doi:10.1016/j.clim.2013.03.014

35. Cutolo M, Capellino S, Sulli A, et al. Estrogens and autoimmune diseases. Ann N Y Acad Sci. 2006;1089:538-547. doi:10.1196/ annals. 1386.043

36. Iamsumang W, Leerunyakul K, Suchonwanit P. Finasteride and its potential for the treatment of female pattern hair loss: evidence to date. Drug Des Devel Ther. 2020;14:951-959. doi:10.2147/dddt.S240615

37. Suchonwanit P, Iamsumang W, Rojhirunsakool S. Efficacy of topical combination of $0.25 \%$ finasteride and $3 \%$ minoxidil versus $3 \%$ minoxidil solution in female pattern hair loss: a randomized, doubleblind, controlled study. Am J Clin Dermatol. 2019;20(1):147-153. doi:10.1007/s40257-018-0387-0

38. Kasumagic-Halilovic E, Prohic A. Nail changes in alopecia areata: frequency and clinical presentation. J Eur Acad Dermatol Venereol. 2009;23(2):240-241. doi:10.1111/j.1468-3083.2008.02830.x

39. Topal IO, Gungor S, Kocaturk OE, Duman H, Durmuscan M. Nail abnormalities in patients with vitiligo. An Bras Dermatol. 2016;91 (4):442-445. doi:10.1590/abd1806-4841.20164620

40. Lee S, Kim BJ, Lee YB, Lee WS. Hair regrowth outcomes of contact immunotherapy for patients with alopecia areata: a systematic review and meta-analysis. JAMA Dermatol. 2018;154(10):1145-1151. doi:10.1001/jamadermatol.2018.2312

41. Mahasaksiri T, Kositkuljorn C, Anuntrangsee T, Suchonwanit P. Application of topical immunotherapy in the treatment of alopecia areata: a review and update. Drug Des Devel Ther. 2021;15:12851298. doi: $10.2147 /$ dddt.S297858

42. Sriphojanart T, Khunkhet S, Suchonwanit P. A retrospective comparative study of the efficacy and safety of two regimens of diphenylcyclopropenone in the treatment of recalcitrant alopecia areata. Dermatol Reports. 2017;9(2):7399. doi:10.4081/dr.2017.7399

43. Suchonwanit P, Kositkuljorn C, Mahasaksiri T, Leerunyakul K. A comparison of the efficacy and tolerability of three corticosteroid treatment regimens in patients with alopecia areata. $J$ Dermatolog Treat. 2020;1-6. doi:10.1080/09546634.2020.1773384

44. Hordinsky M, Ericson M. Autoimmunity: alopecia areata. J Investig Dermatol Symp Proc. 2004;9(1):73-78. doi:10.1111/j.10870024.2004.00835.x

45. Tan E, Tay YK, Goh CL, Chin Giam Y. The pattern and profile of alopecia areata in Singapore-a study of 219 Asians. Int J Dermatol. 2002;41(11):748-753. doi:10.1046/j.1365-4362.2002.01357.x

46. Xiao FL, Yang S, Liu JB, et al. The epidemiology of childhood alopecia areata in China: a study of 226 patients. Pediatr Dermatol. 2006;23(1):13-18. doi:10.1111/j.1525-1470.2006.00161.x

47. Kos L, Conlon J. An update on alopecia areata. Curr Opin Pediatr. 2009;21(4):475-480. doi:10.1097/MOP.0b013e32832db986

48. Mohan GC, Silverberg JI. Association of vitiligo and alopecia areata with atopic dermatitis: a systematic review and meta-analysis. JAMA Dermatol. 2015;151(5):522-528. doi:10.1001/jamadermatol.2014.3324

49. Betz RC, Pforr J, Flaquer A, et al. Loss-of-function mutations in the filaggrin gene and alopecia areata: strong risk factor for a severe course of disease in patients comorbid for atopic disease. J Invest Dermatol. 2007;127(11):2539-2543. doi:10.1038/sj.jid.5700915
50. Gilhar A, Paus R, Kalish RS. Lymphocytes, neuropeptides, and genes involved in alopecia areata. J Clin Invest. 2007;117(8):2019-2027. doi:10.1172/JCI31942

51. Barahmani N, Whaley K, Duvic M. Alopecia areata after allogeneic bone marrow transplantation from an affected, human leukocyte antigen-matched sibling. J Am Acad Dermatol. 2003;49(6):1192. doi:10.1016/S0190

52. McElwee KJ, Hoffmann R. Alopecia areata - animal models. Clin Exp Dermatol. 2002;27(5):410-417. doi:10.1046/j.13652230.2002.01075.x

53. Ker J, Hartert TV. The atopic march: what's the evidence? Ann Allergy Asthma Immunol. 2009;103(4):282-289. doi:10.1016/S10811206(10)60526-1

54. Holgate ST. The epithelium takes centre stage in asthma and atopic dermatitis. Trends Immunol. 2007;28(6):248-251. doi:10.1016/j. it.2007.04.007

55. Saylam Kurtipek G, Cihan FG, Erayman Demirbas S, Ataseven A. The frequency of autoimmune thyroid disease in alopecia areata and vitiligo patients. Biomed Res Int. 2015;2015:435947. doi:10.1155/ 2015/435947

56. Conic RZ, Miller R, Piliang M, Bergfeld W, Atanaskova Mesinkovska N. Comorbidities in patients with alopecia areata. J Am Acad Dermatol. 2017;76(4):755-757. doi:10.1016/j.jaad.2016.12.007

57. Bin Saif GA. Severe subtype of alopecia areata is highly associated with thyroid autoimmunity. Saudi Med J. 2016;37(6):656-661. doi:10.15537/Smj.2016.6.13777

58. Han TY, Lee JH, Noh TK, et al. Alopecia areata and overt thyroid diseases: a nationwide population-based study. J Dermatol. 2018;45 (12):1411-1417. doi:10.1111/1346-8138.14648

59. Andersen YM, Egeberg A, Gislason GH, Skov L, Thyssen JP. Autoimmune diseases in adults with atopic dermatitis. $\mathrm{J} \mathrm{Am} \mathrm{Acad}$ Dermatol. 2017;76(2):274-280 e271. doi:10.1016/j.jaad.2016.08.047

60. Drucker AM, Thompson JM, Li WQ, et al. Incident alopecia areata and vitiligo in adult women with atopic dermatitis: nurses' Health Study 2. Allergy. 2017;72(5):831-834. doi:10.1111/all.13128

61. Cheong KA, Chae SC, Kim YS, Kwon HB, Chung HT, Lee AY. Association of thymic stromal lymphopoietin gene $-847 \mathrm{C}>\mathrm{T}$ polymorphism in generalized vitiligo. Exp Dermatol. 2009;18(12):10731075. doi:10.1111/j.1600-0625.2009.00897.x

62. Jariwala SP, Abrams E, Benson A, Fodeman J, Zheng T. The role of thymic stromal lymphopoietin in the immunopathogenesis of atopic dermatitis. Clin Exp Allergy. 2011;41(11):1515-1520. doi:10.1111/ j.1365-2222.2011.03797.x

63. Bassiouny DA, Shaker O. Role of interleukin-17 in the pathogenesis of vitiligo. Clin Exp Dermatol. 2011;36(3):292-297. doi:10.1111/ j.1365-2230.2010.03972.x

64. Eyerich K, Novak N. Immunology of atopic eczema: overcoming the Th1/Th2 paradigm. Allergy. 2013;68(8):974-982. doi:10.1111/ all.12184

65. Suchonwanit P, Rojhirunsakool S, Khunkhet S. A randomized, investigator-blinded, controlled, split-scalp study of the efficacy and safety of a $1550-\mathrm{nm}$ fractional erbium-glass laser, used in combination with topical 5\% minoxidil versus 5\% minoxidil alone, for the treatment of androgenetic alopecia. Lasers Med Sci. 2019;34(9):1857-1864. doi:10.1007/s10103-019-02783-8

66. Triyangkulsri K, Suchonwanit P. Role of janus kinase inhibitors in the treatment of alopecia areata. Drug Des Devel Ther. 2018;12:2323-2335. doi:10.2147/DDDT.S172638

67. Serarslan G, Savas N, Yenin JZ. Is atopy and autoimmunity more prevalent in patients with alopecia areata? A comparative study. J Eur Acad Dermatol Venereol. 2012;26(6):720-723. doi:10.1111/j.14683083.2011.04152.x

68. Kridin K, Shalom G, Comaneshter D, Cohen AD. Is there an association between alopecia areata and systemic lupus erythematosus? A population-based study. Immunol Res. 2020;68(1):1-6. doi:10.1007/ s12026-020-09115-x 
69. Desai MK, Brinton RD. Autoimmune disease in women: endocrine transition and risk across the lifespan. Front Endocrinol (Lausanne). 2019;10:265. doi:10.3389/fendo.2019.00265

70. Cardenas-Roldan J, Rojas-Villarraga A, Anaya JM. How do autoimmune diseases cluster in families? A systematic review and metaanalysis. BMC Med. 2013;11:73. doi:10.1186/1741-7015-11-73

71. Agre K, McCarthy Veach P, Bemmels H, Wiens K, LeRoy BS, Hordinsky M. Familial implications of autoimmune disease: recurrence risks of alopecia areata and associated conditions in first-degree relatives. J Genet Couns. 2020;29(1):35-43. doi:10.1002/jgc4.1178

72. Suchonwanit P, Udompanich S, Thadanipon K, Chanprapaph K. Trichoscopic signs in systemic lupus erythematosus: a comparative study with 109 patients and 305 healthy controls. J Eur Acad Dermatol Venereol. 2019;33(4):774-780. doi:10.1111/jdv.15421

73. Chanprapaph K, Udompanich S, Visessiri Y, Ngamjanyaporn P, Suchonwanit P. Nonscarring alopecia in systemic lupus erythematosus: a cross-sectional study with trichoscopic, histopathologic, and immunopathologic analyses. J Am Acad Dermatol. 2019;81(6):13191329. doi:10.1016/j.jaad.2019.05.053

74. Udompanich S, Chanprapaph K, Suchonwanit P. Hair and scalp changes in cutaneous and systemic lupus erythematosus. Am J Clin Dermatol. 2018;19(5):679-694. doi:10.1007/s40257-018-0363-8

75. Rutnin S, Chanprapaph K, Pakornphadungsit K, et al. Variation of hair follicle counts among different scalp areas: a quantitative histopathological study. Skin Appendage Disorders. 2021:1-7. doi: $10.1159 / 000518434$
76. Wong CK, Ho CY, Li EK, Lam CW. Elevation of proinflammatory cytokine (IL-18, IL-17, IL-12) and Th2 cytokine (IL-4) concentrations in patients with systemic lupus erythematosus. Lupus. 2000;9 (8):589-593. doi:10.1191/096120300678828703

77. Suchonwanit P, Chalermroj N, Khunkhet S. Low-level laser therapy for the treatment of androgenetic alopecia in Thai men and women: a 24-week, randomized, double-blind, sham device-controlled trial. Lasers Med Sci. 2019;34(6):1107-1114. doi:10.1007/s10103-01802699-9

78. Thomas EA, Kadyan RS. Alopecia areata and autoimmunity: a clinical study. Indian J Dermatol. 2008;53(2):70-74. doi:10.4103/00195154.41650

79. Chanprapaph K, Pomsoong C, Tankunakorn J, Eden C, Suchonwanit P, Rutnin S. Comparative Analyses of clinical features, histopathology, and CD123 Immunohistochemistry of oral lupus erythematosus, lichen planus, and other lichenoid lesions. Dermatology. 2021;1-12. doi:10.1159/000517971

80. Ippolito A, Wallace DJ, Gladman D, et al. Autoantibodies in systemic lupus erythematosus: comparison of historical and current assessment of seropositivity. Lupus. 2011;20(3):250-255. doi:10.1177/ 0961203310385738

81. Chan LS, Vanderlugt CJ, Hashimoto T, et al. Epitope spreading: lessons from autoimmune skin diseases. $J$ Invest Dermatol. 1998;110(2):103-109. doi:10.1046/j.1523-1747.1998.00107.x
Journal of Inflammation Research

\section{Publish your work in this journal}

The Journal of Inflammation Research is an international, peerreviewed open-access journal that welcomes laboratory and clinical findings on the molecular basis, cell biology and pharmacology of inflammation including original research, reviews, symposium reports, hypothesis formation and commentaries on: acute/chronic inflammation; mediators of inflammation; cellular processes; molecular mechanisms; pharmacology and novel anti-inflammatory drugs; clinical conditions involving inflammation. The manuscript management system is completely online and includes a very quick and fair peerreview system. Visit http://www.dovepress.com/testimonials.php to read real quotes from published authors. 